\title{
Accuracy of Transvaginal Ultrasonography, Hysteroscopy and Uterine Curettage in Evaluating Endometrial Pathologies
}

\section{Acurácia da ultrassonografia transvaginal, histeroscopia e curetagem uterina na avaliação de patologias endometriais}

\author{
Miriam da Silva Wanderley ${ }^{1}$ Miriam Monteiro Álvares ${ }^{2}$ Maria de Fátima Brito Vogt ${ }^{1}$ \\ Lizandra Moura Paravidine Sazaki \\ ${ }^{1}$ Gynecology and Obstetrics, Faculdade de Medicina, Universidade de \\ Brasília, Brasília, Brazil \\ 2 Service of Gynecology and Obstetrics, Hospital Universitário de \\ Address for correspondence Miriam da Silva Wanderley, Gynecology \\ and Obstetrics, Faculdade de Medicina, Universidade de Brasília, \\ Campus Universitário Darcy Ribeiro, s/n, Asa Norte, 70900-000- \\ Brasília (HUB), Brasília, Brazil \\ Brasília, DF, Brazil (e-mail: miriamsw@unb.br).
}

Rev Bras Ginecol Obstet 2016;38:506-511.
Abstract

\section{Keywords}
- endometrial polyp
- submucous myoma
- endometrial hyperplasia
- transvaginal ultrasonography
- hysteroscopy
- uterine curettage
- accuracy

Objective To evaluate the accuracy of transvaginal ultrasonography, hysteroscopy and uterine curettage in the diagnosis of endometrial polyp, submucous myoma and endometrial hyperplasia, using as gold standard the histopathological analysis of biopsy samples obtained during hysteroscopy or uterine curettage.

Methods Cross-sectional study performed at the Hospital Universitário de Brasília (HUB). Data were obtained from the charts of patients submitted to hysteroscopy or uterine curettage in the period from July 2007 to July 2012 .

Results One-hundred and ninety-one patients were evaluated, 134 of whom underwent hysteroscopy, and 57, uterine curettage. Hysteroscopy revealed a diagnostic accuracy higher than $90 \%$ for all the diseases evaluated, while transvaginal ultrasonography showed an accuracy of $65.9 \%$ for polyps, $78.1 \%$ for myoma and $63.2 \%$ for endometrial hyperplasia. Within the 57 patients submitted to uterine curettage, there was an accuracy of $56 \%$ for polyps and $54.6 \%$ for endometrial hyperplasia.

Conclusion Ideally, after initial investigation with transvaginal ultrasonography, guided biopsy of the lesion should be performed by hysteroscopy, whenever necessary, in order to improve the diagnostic accuracy and subsequent clinical management. received

May 11, 2016

accepted

September 2, 2016

published online

October 21, 2016
DOI http://dx.doi.org/

$10.1055 / \mathrm{s}-0036-1593774$. ISSN 0100-7203.
Copyright $\odot 2016$ by Thieme Publicações License terms

Ltda, Rio de Janeiro, Brazil
(®) $\Theta \circledast$ 


\section{Resumo}

\section{Palavras-chave}

- pólipo endometrial

- mioma submucoso

- hiperplasia endometrial

- ultrassonografia transvaginal

- histeroscopia

- curetagem uterina

- acurácia
Objetivo avaliar a acurácia da ultrassonografia transvaginal, da histeroscopia e da curetagem uterina no diagnóstico de pólipo endometrial, mioma submucoso e hiperplasia de endométrio, utilizando como padrão-ouro a análise histopatológica de amostras obtidas por biópsia realizada durante a histeroscopia ou a curetagem.

Métodos estudo transversal realizado no Hospital Universitário de Brasília (HUB), cujas informações foram obtidas nos prontuários das pacientes que foram submetidas à histeroscopia ou curetagem uterina no período de julho de 2007 a julho de 2012. Resultados Foram avaliadas 191 pacientes, sendo que 134 foram submetidas à histeroscopia e 57 à curetagem uterina. Observou-se acurácia diagnóstica maior que $90 \%$ para todas as patologias avaliadas por histeroscopia, enquanto que por ultrassonografia transvaginal observou-se acurácia de $65,9 \%$ para pólipo, $78,1 \%$ para mioma e $63,2 \%$ para hiperplasia endometrial. Nas 57 pacientes submetidas a curetagem uterina, observou-se acurácia de $56 \%$ para pólipo e de $54,6 \%$ para hiperplasia endometrial.

Conclusão Idealmente, após a investigação inicial com ultrassonografia transvaginal, deveria, sempre que necessário, ser realizada histeroscopia com biópsia guiada da lesão, o que melhoraria a acurácia diagnóstica e posterior conduta clínica.

\section{Introduction}

Uterine pathologies, such as endometrial polyps, myomas, synechiae, hyperplasia and endometrial cancer, are relatively frequent morbidities in the female population, both in reproductive-aged women and postmenopausal ones. ${ }^{1}$

The available methods for evaluation of the uterine cavity have developed considerably over the last few years. Transvaginal ultrasonography is currently used as a method of choice for investigation of the endometrium, either in cases of genital bleeding, or for screening in asymptomatic women, especially in the postmenopause. ${ }^{2}$ It is a non-invasive method, well tolerated by patients and it allows immediate interpretation of the observed images. However, there are conflicting reports regarding its diagnostic accuracy. ${ }^{3-5}$

Hysteroscopy has the advantage of providing a direct visualization of the uterine cavity and the endometrium, allowing guided biopsy of any suspected lesion. However, it is an invasive procedure, relatively expensive, which demands specific equipment and trained staff and even in big cities it is not available for the entire population.

Uterine curettage has been, for decades, the universal procedure for diagnosis of intrauterine diseases. Although simpler than the former, it is an invasive procedure as well. It has the disadvantage of being blind, therefore, the surgeon is not able to remove or even detect the entire lesion. However, one cannot ignore the fact that it is a procedure available in the vast majority of Brazil's public health services and the gynecologists, in general, are entitled to perform it.

The present study aims to evaluate the accuracy of transvaginal ultrasonography, hysteroscopy and uterine curettage in the diagnosis of endometrial polyp, submucous myoma, and endometrial hyperplasia, using as gold standard the histopathological analysis of biopsy sample obtained during hysteroscopy or uterine curettage.

\section{Methods}

This is a cross-sectional study performed at the Hospital Universitário de Brasília (HUB). Data were obtained from the charts of patients submitted to hysteroscopy or uterine curettage in the period from July 2007 to July 2012.

According to the inclusion criteria, the subjects of the study were women with ultrasound scans performed at HUB and/or other health public services of the Federal District whose diagnoses were compatible with endometrial polyp, endometrial thickening or submucous myoma. For the purposes of assessment of endometrial thickness, the maximum of $5 \mathrm{~mm}$ in postmenopausal women, and $15 \mathrm{~mm}$ in premenopausal were considered normal. ${ }^{6,7}$

The exclusion criteria were: patients suffering from pathologies other than those mentioned above; those lacking the reports of the transvaginal ultrasonography and hysteroscopy and those missing histopathological reports obtained during hysteroscopy or uterine curettage; patients with cervical diseases; patients with pelvic inflammatory disease; patients with previous diagnosis of endometrial carcinoma or in treatment for endometrial hyperplasia, and patients under 18 years of age.

Submucous myoma cases found in transvaginal ultrasonography reports were referred to hysteroscopy, while the surgical indication for polyp and endometrial thickening depended on the availability of the method at the time.

Hysteroscopy was performed under spinal anesthesia or sedation using a $30^{\circ}$ hysteroscope with a $5 \mathrm{~mm}$ diagnostic sheath.The uterinecavity was distended with $3 \%$ mannitoland endometrial biopsies were taken under direct vision using a resectoscope. Uterine curettage was also performed under spinal anesthesia or sedation with conventional curette and blind biopsy of the uterine cavity. 
Transvaginal ultrasonography and hysteroscopy reports compatible with endometrial thickening were related to endometrial hyperplasia for the purposes of histopathological analysis.

Sensitivity, specificity, positive predictive value, negative predictive value and accuracy of transvaginal sonography, hysteroscopy and uterine curettage were calculated. Data were given a $95 \%$ confidence interval and histopathological reports were considered as the gold standard. For these procedures STATA Statistical Software version 11.0 (StataCorp LP, College Station, TX) was employed.

The study was approved by the Committee of Ethics in Research in Human Beings of the Faculdade de Ciências da Saúde da Universidade de Brasília (179/2011 record).

\section{Results}

A total of 191 women were enrolled in the study, 134 of whom underwent hysteroscopy and 57, uterine curettage. The mean age of the patients was $49 \pm 12$ years old (range 25 to 86 years), 99 were married and 70 were multiparous ( $\geq 4$ pregnancies).

In terms of symptoms, 101 patients (52.9\%) were asymptomatic, 69 reported abnormal uterine bleeding, 13 had chronic pelvic pain, 3 reported dyspareunia and 11 had varied complaints, that is, the patient reported more than one symptom.

Of the 134 patients with abnormal findings in the transvaginal ultrasonography who underwent hysteroscopy, 25 showed normal uterine cavity. Of the 48 patients whose transvaginal ultrasonography revealed endometrial thickening, hysteroscopy diagnosed 16 polyps, 3 myomas and 12 cases of normal endometrium ( - Table 1 ).

Hysteroscopy revealed diagnostic accuracy higher than $90 \%$ for all the evaluated diseases, while transvaginal ultrasonography demonstrated accuracy of $65.9 \%$ for polyp, $78.1 \%$ for myoma and $63.2 \%$ for endometrial hyperplasia (-Table 2 ).

In 26 of the 57 patients whose transvaginal ultrasonography had revealed polyps, and who underwent uterine curettage, a histopathological diagnosis could be confirmed in 14 cases; in 6 of them, there was normal endometrium, and in 2 , there was insufficient material for evaluation. In 15 cases, in which normal endometrium was observed by histopathologic analysis, transvaginal ultrasonography detected polyp or endometrial thickening (-Table 3 ).
It was observed accuracy of $56 \%$ for polyp and $54.6 \%$ for endometrial hyperplasia in 57 patients who underwent uterine curettage ( - Table 4 ).

\section{Discussion}

Transvaginal ultrasonography revealed sensitivity of $71.4 \%$ for endometrial polyp and $57.9 \%$ for submucous myoma, while specificity was 60.3 and $98.2 \%$, respectively, in our study. Great variability has been observed in the literature, both in sensitivity and specificity, for the diagnosis of these pathologies. ${ }^{1,8-10}$ In addition, the accuracy of the method was shown to be moderate in the diagnosis of endometrial polyp and submucous myoma, similarly to other studies. ${ }^{1,8}$

Ultrasound examination is a noninvasive diagnostic method, well tolerated, relatively low-cost and universally considered the first choice in the initial evaluation of uterine structural pathologies. ${ }^{11}$ However, the ability of transvaginal ultrasonography to distinguish among the many causes of thickened endometrium has been questioned, ${ }^{8,12}$ and various endometrial pathologies with a significant number of false positive and false negative diagnoses have been observed, particularly polyps and endometrial hyperplasia. ${ }^{8,13}$

In this study, only 17 of the 48 patients whose transvaginal ultrasonography revealed endometrial thickening, who subsequently underwent hysteroscopy and biopsy, effectively presented endometrial hyperplasia. Polyps, small myomas and normal endometrium were masked by a thick endometrium. Similarly, of the 71 polyps demonstrated in the transvaginal ultrasonography, only 37 were confirmed by biopsy performed during hysteroscopy. The findings of the ultrasound examination, therefore, led to a considerable number of false positive diagnoses concerning endometrial hyperplasia $(\mathrm{PPV}=15.6 \%)$ and endometrial polyp $(\mathrm{PPV}=62.5 \%)$.

The diagnostic accuracy of the method was $63.2 \%$ for endometrial hyperplasia, with sensitivity of $58.3 \%$ and specificity of $68.1 \%$, lower than the results of Soguktas et $\mathrm{al}^{6}$ and Bingol et $\mathrm{al}^{8}$ and similar to those of Grimbizis et $\mathrm{al}^{10}$, while Kasraeian et $\mathrm{al}^{2}$ observed sensitivity of $55 \%$ for simple hyperplasia and $44.4 \%$ for atypical hyperplasia.

In addition, although 4 histopathological reports of endometrial cancer have been observed, no ultrasound report was suggestive of malignancy in 191 exams performed, similarly to the study of Grimbizis et $\mathrm{al}^{10}$, in which transvaginal

Table 1 Agreement between transvaginal ultrasonography and hysteroscopy performed in 134 patients

\begin{tabular}{|c|c|c|c|c|c|c|}
\hline \multirow[t]{2}{*}{ Transvaginal Ultrasonography } & \multicolumn{6}{|c|}{ Hysteroscopy } \\
\hline & Polyp & Hyperplasia & Myoma & Normal & Others & Total \\
\hline Polyp & 37 & 19 & 3 & 11 & 1 & 71 \\
\hline Hyperplasia & 16 & 17 & 3 & 12 & - & 48 \\
\hline Myoma & - & - & 11 & 1 & - & 12 \\
\hline Others & - & 2 & - & 1 & - & 3 \\
\hline Total & 53 & 38 & 17 & 25 & 1 & 134 \\
\hline
\end{tabular}


Table 2 Diagnostic accuracy parameters (\%) of transvaginal ultrasonography and hysteroscopy performed in 134 patients (95\% confidence interval)

\begin{tabular}{|c|c|c|}
\hline & Transvaginal Ultrasonography & Hysteroscopy \\
\hline \multicolumn{3}{|c|}{ Endometrial polyp } \\
\hline Sensibility (\%) & $71.4(58.7-82.1)$ & $84.4(73.1-92.2)$ \\
\hline Specificity (\%) & $60.3(47.7-72)$ & $100(94.9-100)$ \\
\hline $\mathrm{PPV}^{*}(\%)$ & $62.5(50.3-73.6)$ & $100(93.4-100)$ \\
\hline $\mathrm{NPV}^{* *}(\%)$ & $69.5(56.1-80.8)$ & $87.5(78.2-93.8)$ \\
\hline Accuracy (\%) & $65.9(57.7-74)$ & $92.2(87.7-96.7)$ \\
\hline \multicolumn{3}{|c|}{ Submucous myoma } \\
\hline Sensibility (\%) & $57.9(33.5-79.7)$ & $89.5(66.9-98.7)$ \\
\hline Specificity (\%) & $98.2(93.7-99.8)$ & $100(96.8-100)$ \\
\hline $\mathrm{PPV}^{*}(\%)$ & $84.6(54.6-98.1)$ & $100(80.5-100)$ \\
\hline $\mathrm{NPV}^{* *}(\%)$ & $93.2(87.1-97)$ & $98.3(94-99.8)$ \\
\hline Accuracy & $78.1(66.6-89.5)$ & $94.7(87.6-100)$ \\
\hline \multicolumn{3}{|c|}{ Endometrial hyperplasia } \\
\hline Sensibility (\%) & $58.3(27.7-84.8)$ & $100(75.3-100)$ \\
\hline Specificity (\%) & $68.1(58.9-76.3)$ & $80.2(71.9-86.9)$ \\
\hline $\mathrm{PPV}^{*}(\%)$ & $15.6(6.4-29.5)$ & $35.1(20.2-52.5)$ \\
\hline $\mathrm{NPV}^{* *}(\%)$ & $94.2(87-98.1)$ & $100(96.3-100)$ \\
\hline Accuracy (\%) & $63.2(48-78.4)$ & $90.1(86.5-93.6)$ \\
\hline
\end{tabular}

*PPV-positive predictive value;

"NPV-negative predictive value.

Table 3 Agreement between transvaginal ultrasonography and histological diagnosis after uterine curettage performed in 57 patients

\begin{tabular}{|c|c|c|c|c|c|c|}
\hline \multirow[t]{2}{*}{ Transvaginal Ultrasonography } & \multicolumn{6}{|c|}{ Histological Diagnosis } \\
\hline & Polyp & Hyperplasia & Myoma & Normal & $\begin{array}{l}\text { Others/ } \\
\text { Inconclusive }\end{array}$ & Total \\
\hline Polyp & 14 & 3 & 1 & 6 & 2 & 26 \\
\hline Hyperplasia & 11 & 6 & 1 & 9 & 3 & 30 \\
\hline Others/Inconclusive & 1 & - & - & - & - & 1 \\
\hline Total & 26 & 9 & 2 & 15 & 5 & 57 \\
\hline
\end{tabular}

Table 4 Uterine curettage accuracy (\%) for diagnosing endometrial polyp and endometrial hyperplasia in 57 patients (95\% confidence interval)

\begin{tabular}{|l|l|l|}
\hline & Endometrial polyp & Endometrial hyperplasia \\
\hline Sensibility (\%) & $52(31.3-72.2)$ & $62.5(24.5-91.5)$ \\
\hline Specificity (\%) & $60(40.6-77.3)$ & $46.8(32.1-61.9)$ \\
\hline PPV $\left.^{*} \%\right)$ & $52(31.3-72.2)$ & $16.7(5.6-34.7)$ \\
\hline NPV $^{* *}(\%)$ & $60(40.6-77.3)$ & $88(68.8-97.5)$ \\
\hline Accuracy (\%) & $56(43-69)$ & $54.6(35-74)$ \\
\hline
\end{tabular}

*PPV-positive predictive value;

"NPV-negative predictive value. 
ultrasonography was also not able to discriminate hyperplasia or endometrial cancer from other intracavitary lesions.

Hysteroscopy, on the other hand, presented diagnostic accuracy higher than $90 \%$ in all the studied pathologies. Similar results, demonstrating the superiority of this examination versus transvaginal ultrasonography in terms of diagnosis of those endometrial pathologies have been observed, ${ }^{3,6,8,10}$ although other studies ${ }^{5,9}$ have concluded that the combination of both methods did not seem to improve the results regarding endometrial polyps.

However, it must not be forgotten that hysteroscopy is an invasive procedure, usually performed under anesthesia and an operator-dependent technique. Physicians were not always able to distinguish easily a proliferative endometrium from a hyperplasic one. ${ }^{14}$ A polypoid functional endometrium can mimic small polyps. ${ }^{15}$ Endometrial hyperplasia does not have specific hysteroscopy presentation, and may present as "polyp-like" lesion, or an irregularly thick endometrium. ${ }^{16}$ Thus, although the feasibility of hysteroscopy as a "one stop diagnosis" method ${ }^{17}$ is still debated, the most accepted argument seems to be that, in all cases, an endometrial biopsy sample should be obtained during the procedure to confirm the diagnosis. ${ }^{15,18}$

We agree with that approach, especially given that the four endometrial cancers diagnosed in the histopathology analysis were not observed in the hysteroscopy, perhaps hidden amid a thickened endometrium. Besides, the positive predictive values of both hysteroscopy and transvaginal ultrasonography, regarding endometrial hyperplasia, were very low. Corroborating these findings, de Borges et $\mathrm{al}^{19}$ observed that both techniques showed low accuracy in predicting malignancy in focal lesions.

The high sensitivity and specificity observed in our analysis, similarly to other studies ${ }^{20,21}$, indicated that hysteroscopy is a valuable tool for diagnosing polyp and myoma. However, Clark et $\mathrm{al}^{22}$ pointed out that hysteroscopy may not be the best tool for evaluating endometrial hyperplasia, and recent meta-analysis ${ }^{16}$ concluded that hysteroscopy seemed more capable to exclude endometrial hyperplasia than to positively identify it.

In the diagnosis of polyps and endometrial hyperplasia, uterine curettage demonstrated accuracy of $56 \%$ and $54.6 \%$, respectively, which is lower than the accuracy found in transvaginal ultrasonography. And it is known that, in both methods, small structural abnormalities may not be properly diagnosed or the exact location of the lesion may not be set or assessed. ${ }^{15}$

Karageyim Karsidag et $\mathrm{al}^{15}$ observed sensitivity of $47 \%$, specificity of $68 \%$, and accuracy of $58 \%$ in diagnosing intracavitary abnormalities in uterine curettage, and $65 \%$ of endometrial polyps and submucous myomas were missed in the procedure. Similarly, Epstein et $\mathrm{al}^{23}$ observed that curettage failed to detect $58 \%$ of polyps, $50 \%$ of hyperplasia and $11 \%$ of endometrial cancers. In another study, ${ }^{24} 52.7 \%$ of intrauterine disorders have not been diagnosed by blind curettage.

We found that 9 out of the 30 patients who underwent uterine curettage due to endometrial thickening at transvaginal ultrasonography presented normal endometrium in the histopathological analysis. However, it does not mean that the samples represent exactly the whole intrauterine cavity tissue. Bettocchi et $\mathrm{al}^{25}$ observed that major intrauterine diseases were missed in $62.5 \%$ of the cases and all endometrial disorders were presented in the hysterectomy specimens. In the study of Lee et $\mathrm{al}^{26}$, only $5.1 \%$ of endometrial polyps were diagnosed by curettage.

In addition, recent meta-analysis and systematic review ${ }^{27}$ observed that in women with postmenopausal bleeding, endometrial sampling obtained by curettage or hysteroscopy to detect benign or malignant endometrial diseases has very low sensitivity and greater efforts are necessary to correctly diagnose focal pathologies, particularly after a benign result.

Some limitations of our study must be mentioned. The first is that $52.9 \%$ of the patients were asymptomatic. However, in studies that evaluated asymptomatic patients, symptomatic patients, or both, the results did not differ substantially from ours regarding the accuracy of the diagnostic methods. ${ }^{1,2,8-10,15}$

Since high frequency ultrasound examination has been performed in outpatients, an increased number of intracavitary disorders or thickened endometrium has been identified in asymptomatic women. However, there is still no consensus on when a histological evaluation is needed. ${ }^{28}$

Current guidelines about how to deal with the finding of a thick endometrial echo in the ultrasound exam of nonbleeding postmenopausal patients does not automatically require a sample tissue examination. ${ }^{29}$ Nevertheless, Kasraeian et $\mathrm{al}^{2}$ observed that $17.4 \%$ of asymptomatic postmenopausal women had some kind of endometrial pathology detected by endometrial biopsy and postulated the importance of that finding, since the patients can remain asymptomatic for a long period of time, and early detection of carcinomas and hyperplasia could improve patients' prognosis.

Although we had observed 16 normal endometria (proliferative or secretory ones) and 7 myomas, 11 cases simple of hyperplasia were also observed, with and without atypia, besides an endometrial carcinoma in an asymptomatic patient.

Another limitation is that the transvaginal ultrasonography exams were performed by different professionals in distinct healthcare clinics of the Federal District, and the uterine curettages were performed by doctors with varying degrees of experience, including residents. Paradoxically, this is also where the strength of our study lies, since it reflects a common situation of public services in our region.

Hysteroscopy was performed whenever possible, but because of the limited availability of hysteroscopes and of well trained professionals in our service, the substantial increase in the demand for the procedure, the lack of equipment or qualified physicians in other hospitals, and the need of a proactive action, a considerable number of uterine curettages had to be performed instead.

However, this strategy proved not to be the best, as intracavitary lesions were found in $77.7 \%$ of the 27 patients submitted to transvaginal ultrasonography after uterine curettage. Similarly, Epstein et $\mathrm{al}^{23}$, whose approach consisted in performing hysteroscopy after curettage, observed that $87 \%$ of focal lesions remained in the cavity, and Bettocchi et $\mathrm{al}^{25}$, analyzing species of hysterectomy after curettage, 
observed that all uterine disorders were still present in the uterus removed.

Despite the size of the sample, our results confirm the inadequacy of uterine curettage as a diagnostic and therapeutic tool for intrauterine diseases. The results also reinforce the need for greater investments in training and enabling physicians and residents to perform hysteroscopy, as this procedure allows direct visualization of the cavity and sampling of any possible suspicious lesions, which would improve the diagnostic accuracy and subsequent clinical conduct.

Thus, ideally, after a transvaginal ultrasonography as first procedure, if necessary, a hysteroscopy with directed biopsy should be performed. The adoption of this measure is expected to improve the diagnostic accuracy and later clinical management.

\section{Acknowledgments}

We are grateful to Juliana Costa Rezende and João Paulo Costa Rezende for assistance with English translation.

\section{References}

1 Yela DA, Hidalgo SR, Pereira KCHM, Gabiatti JRE, Monteiro IMU. Comparative study of transvaginal sonography and outpatient hysteroscopy for the detection of intrauterine diseases. Acta Med Port 2011;24(Suppl 2):65-70

2 Kasraeian M, Asadi N, Ghaffarpasand F, Karimi AA. Value of transvaginal ultrasonography in endometrial evaluation of non-bleeding postmenopausal women. Climacteric 2011;14(1):126-131

3 Kelekci S, Kaya E, Alan M, Alan Y, Bilge U, Mollamahmutoglu L. Comparison of transvaginal sonography, saline infusion sonography, and office hysteroscopy in reproductive-aged women with or without abnormal uterine bleeding. Fertil Steril 2005;84(3):682-686

4 Dreisler E, Sorensen SS, Ibsen PH, Lose G. Value of endometrial thickness measurement for diagnosing focal intrauterine pathology in women without abnormal uterine bleeding. Ultrasound Obstet Gynecol 2009;33(3):344-348

5 Babacan A, Gun I, Kizilaslan C, et al. Comparison of transvaginal ultrasonography and hysteroscopy in the diagnosis of uterine pathologies. Int J Clin Exp Med 2014;7(3):764-769

6 Soguktas S, Cogendez E, Kayatas SE, Asoglu MR, Selcuk S, Ertekin A. Comparison of saline infusion sonohysterography and hysteroscopy in diagnosis of premenopausal women with abnormal uterine bleeding. Eur J Obstet Gynecol Reprod Biol 2012;161(1): 66-70

7 Kang SK, Giovanniello G, Kim S, Bedell S, Babb JS, Bennett GL. Performance of multidetector CT in the evaluation of the endometrium: Measurement of endometrial thickness and detection of disease. Clin Radiol 2014;69(11):1123-1128

8 Bingol B, Gunenc MZ, Gedikbasi A, Guner H, Tasdemir S, Tiras B. Comparison of diagnostic accuracy of saline infusion sonohysterography, transvaginal sonography and hysteroscopy in postmenopausal bleeding. Arch Gynecol Obstet 2011;284(1): 111-117

9 Vitner D, Filmer S, Goldstein I, Khatib N, Weiner Z. A comparison between ultrasonography and hysteroscopy in the diagnosis of uterine pathology. Eur J Obstet Gynecol Reprod Biol 2013;171(1): 143-145

10 Grimbizis GF, Tsolakidis D, Mikos T, et al. A prospective comparison of transvaginal ultrasound, saline infusion sonohysterography, and diagnostic hysteroscopy in the evaluation of endometrial pathology. Fertil Steril 2010;94(7):2720-2725
11 Niknejadi M, Haghighi H, Ahmadi F, et al. Diagnostic accuracy of transvaginal sonography in the detection of uterine abnormalities in infertile women. Iran J Radiol 2012;9(3):139-144

12 B. T V, Shivalingaiah N. Role of transvaginal sonography and diagnostic hysteroscopy in abnormal uterine bleeding. J Clin Diagn Res 2014;8(12):OC06-OC08

13 Chawla I, Tripathi S, Vohra P, Singh P. To evaluate the accuracy of saline infusion sonohysterography (SIS) for evaluation of uterine cavity abnormalities in patients with abnormal uterine bleeding. J Obstet Gynaecol India 2014;64(3):197-201

14 Fay TN, Khanem N, Hosking D. Out-patient hysteroscopy in asymptomatic postmenopausal women. Climacteric 1999;2(4): 263-267

15 Karageyim Karsidag AY, Buyukbayrak EE, Kars B, Unal O, Turan MC. Transvaginal sonography, sonohysterography, and hysteroscopy for investigation of focal intrauterine lesions in women with recurrent postmenopausal bleeding after dilatation \& curettage. Arch Gynecol Obstet 2010;281(4):637-643

16 Gkrozou F, Dimakopoulos G, Vrekoussis T, et al. Hysteroscopy in women with abnormal uterine bleeding: a meta-analysis on four major endometrial pathologies. Arch Gynecol Obstet 2015; 291(6):1347-1354

17 Gan DEY, Jawan RA, Moy FM. Concordance between hysteroscopic impression and endometrial histopathological diagnosis. Prev Med 2013;57(Suppl):S21-S23

18 Zinna M, Gentile M, Torcia F, et al. Diagnostic accuracy of sonohysterography vs hysteroscopy in benign uterine endocavitary findings. Eur Rev Med Pharmacol Sci 2015;19(3):365-371

19 de Godoy Borges PC, Dias R, Bonassi Machado R, Borges JBR, Spadoto Dias D. Transvaginal ultrasonography and hysteroscopy as predictors of endometrial polyps in postmenopause. Womens Health (Lond) 2015;11(1):29-33

20 Elfayomy AK, Habib FA, Elkablawy MA. Role of hysteroscopy in the detection of endometrial pathologies in women presenting with postmenopausal bleeding and thickened endometrium. Arch Gynecol Obstet 2012;285(3):839-843

21 van Dongen H, de Kroon CD, Jacobi CE, Trimbos JB, Jansen FW. Diagnostic hysteroscopy in abnormal uterine bleeding: a systematic review and meta-analysis. BJOG 2007;114(6): 664-675

22 Clark TJ, Voit D, Gupta JK, Hyde C, Song F, Khan KS. Accuracy of hysteroscopy in the diagnosis of endometrial cancer and hyperplasia: a systematic quantitative review. JAMA 2002;288(13): 1610-1621

23 Epstein E, Ramirez A, Skoog L, Valentin L. Dilatation and curettage fails to detect most focal lesions in the uterine cavity in women with postmenopausal bleeding. Acta Obstet Gynecol Scand 2001; 80(12):1131-1136

24 Yarandi F, Izadi-Mood N, Eftekhar Z, Shojaei H, Sarmadi S. Diagnostic accuracy of dilatation and curettage for abnormal uterine bleeding. J Obstet Gynaecol Res 2010;36(5):1049-1052

25 Bettocchi S, Ceci O, Vicino M, Marello F, Impedovo L, Selvaggi L. Diagnostic inadequacy of dilatation and curettage. Fertil Steril 2001;75(4):803-805

26 Lee DO, Jung MH, Kim HY. Prospective comparison of biopsy results from curettage and hysteroscopy in postmenopausal uterine bleeding. J Obstet Gynaecol Res 2011;37(10):1423-1426

27 van Hanegem N, Prins MM, Bongers MY, et al. The accuracy of endometrial sampling in women with postmenopausal bleeding: a systematic review and meta-analysis. Eur J Obstet Gynecol Reprod Biol 2016;197:147-155

28 Schmidt T, Breidenbach M, Nawroth F, et al. Hysteroscopy for asymptomatic postmenopausal women with sonographically thickened endometrium. Maturitas 2009;62(2):176-178

29 Goldstein SR. The role of transvaginal ultrasound or endometrial biopsy in the evaluation of the menopausal endometrium. Am J Obstet Gynecol 2009;201(1):5-11 